\title{
Outcome Based Education (OBE) - Trend Review
}

\author{
RashaEldeeb and NishaShatakumari \\ Department of Physiology, Gulf Medical University (GMU), Ajman, UAE.
}

\begin{abstract}
The reform in the health services that stresses on professionalism had brought the necessity to adopt outcome based education $(O B E)$ in medical education. It is an approach of education that clearly identifies its intended final product - students' competencies by determining the final curriculum outcome - a head of planning the framework of the curriculum. The unambiguous outcome is used to plan the curriculum, monitor its implementation, evaluate it and assess student's achievement. The present paper is review of the origin, advantages, disadvantages, pitfalls and guidelines in implementation of outcome-based education. It is an attempt to provide a comprehensive coverage of a very popular current trend in medical education.
\end{abstract}

Key words: outcome-based education, medical education trends, curriculum planning

\section{Introduction}

With contrary to the fact that most teachers put the center of their attention too much on what they teach rather than on what their students learn, OBE emphasizes on what is expected from the student to finally achieve when they complete their courserather than how they achieved it.

Outcome based education is defined as an approach to education in which decisions about the curriculum are driven by the outcomes the students should display by the end of the course- professional knowledge, skills, abilities, values and attitudes- rather than on the educational process. It highlights the fact that you have to know the final destination of your journey before you start voyaging [1,2]

\section{Origin of the outcome based education (OBE)}

OBE has been adopted for more than a century when educators brought to light the importance of appreciating students' individual variation in the learning process, believing that education is best measured by encouraging individual students' achievement that could occur at different rates for different students. OBE allows the students of different abilities to learn at their own rates with an emphasis on programmatic outcome in professional medical knowledge, skills and attitudes [3, 4].

The concept of OBE was also encouraged by the reform in the health care system that stresses on establishing a common set of standards for doctors with highlighting the fact that professionalism should be an essential competency achieved by the medical student before graduating [5]. With the increasingly global marketplace for higher education, OBE has been adopted by many medical schools with a great interest to ensure that the degrees granted to their students are competitive and accredited internationally and their graduate are competent practicing physicians [6,7].

\section{Nature of the outcome based education (OBE)}

Outcome-based education approaches the curriculum decision making based on the competencies students should demonstrate at the end of their educational program, thus the outcomes or competencies dictate the curriculum content and organization, the teaching methods and strategies, the course offered, the educational environment and the assessment strategies [8]. All curriculum and teaching decisions are made based on how best to facilitate the desired final outcome $[9,10]$.

Steps for planning and implementing outcome based curriculum:

1. Deciding on the outcomes: the educational outcomes are clearly identified and unambiguously specified regarding the content, context and competence. The US Accreditation Council on Graduate Education [11],lumps the outcomes into a set of general competencies addressing patient care, medical knowledge, practice-based learning and improvement, system-based practice, interpersonal and communication skills and professionalism [12].

2. Demonstrating outcomes: the expected outcome should be defined by setting 'benchmarks' for each level of the program. Each benchmark is a skill that must be demonstrated by the student. Benchmarks should tackle and define specifically the goals of the curriculum and verify ways to assess whether students have reached these goals at that level of study.

3. Deciding on contents and teaching strategies OBE can be implemented as a 'Whole-class' models which aim to bring all learners in a classroom up to high levels of learning before proceeding further or by the 
'Flexible' models which use flexible grouping, continuous progress, technological approaches and instructional management $[9,10]$.

4. Assessments in OBE: OBE is driven by assessments that focus on well-defined learning outcomes and not by other factors such as what is taught, the duration taken by the student to achieve the outcomes or which path the students take to achieve their targets [13]. In OBE standard-referenced assessment could be used which is similar to criterion - referenced assessment but with clearer description of expected performance and since OBE requires ongoing feedback between the student and the lecturer, continuous assessments and student portfolios would be of a great help in assessing OBE[12].

\section{Advantages}

The adoption of OBE is perceived as a valuable addition to the educational process believing that with its clear specified outcomes it encourages participation and collaboration from multiple disciplines and interest groups in planning and implementing the curricula which will foster learning in various areas of medical practice.

Educators believe that OBE does not only guaranty the clarity and assures the absence of controversy in curricula planning but also its relevance to the students' future practice. The clear, straightforward outcomes provided by OBE form a framework for decision - making and guidelines for assessment and program evaluation $[2,4]$.

The educators who support OBE in medical education believe that the presence of specific, unambiguous outcomes, enables OBE to promote more self-directed learning and allow students to have a metacognitive understanding of the educational program and their role in that process. It also encourages active discussion of those goals and the values they embrace.

\section{Disadvantages}

The shift to OBE has attracted lots of opposition. Opponents believed that, education should be an open ended and should not be constrained by outcomes and that education should be valued for its own sake, not because it leads to some outcome. They believe that defining education as a set of outcomes - decided in advance of teaching and learning - conflicts with the wonderful, unpredictable voyages of exploration that characterize learning through discovery and inquiry. They mistakenly assume that teaching will be inappropriately limited by this model. Moreover they are arguing and emphasizing on what they believe; that the inclusion and emphasis on attitudes and values in stated outcomes is inappropriate $[4,14]$

Critics of OBE object to the use of standardized tests thinking that it is unfair to use the same level of work or to use the same achievement tests for impoverished or racially disadvantaged students as they do for more advantaged students. They also claim that the OBE approach does not permit special, lower standards for students who have been badly served by public education in the past.

Regarding the outcomes, many opponents dislike them because they think the outcomes' standards maybe too easy, too hard, or wrongly conceived. In addition, some critics object to additional resources being spent on the struggling students. Furthermore, some teachers find their grading workload significantly increases in OBE curriculum [14]

\section{Pitfalls in implementation}

While implementing OBE we have to clear certain obstacle that we may face:

- The Unclear and ambiguous setting of certain outcomes either for the teacher, student or both hinder student achievement and teacher contribution in the curriculum.

- The teachers' unawareness of the curriculum's outcome will limit the collaboration and cooperation between the faculties to reach a common goal; creating a state of traditionalism and faculty resistance.

- The improper assessment tool that doesn't match the aimed outcome or that doesn't consider the variability in student's achievement.

\section{Guideline to implement OBE}

For a successful of OBE program collaborative effort from administrators, educators, parent, teachers and students should be sought to assure a successful planning and implementation and to guarantee commitment and decrease resistance.

The basic characteristics and principles for OBE implementation would include:

- A clear institutional endorsed mission statement that reflects commitment to success for all the students and provides the means for translating that commitment into action.

- Clearly defined 'exit outcomes' that issued to articulate the curriculum framework of the program and that convey what students must demonstrate before they graduate. 
- Engagement of large, complex and geographically dispersed faculty staff in an extended period of highly collaborative, cross-disciplinary dialogue, innovative thinking and planning to assure ownership and full commitment of the faculties.

- A system of instructional decision making and delivery that employs a variety of methods to assure successful demonstration of all outcomes and to provide more than one chance for students to be successful.

- Multiple instructional and assessment strategies that meet the needs of each student with allowing adequate time and assistance for each student to reach the maximum potential.

- A criterion-referenced system of assessment and an ongoing system of improvement programs that ensure staff accountability, effective leadership and staff collaboration with a data base of significant, visionary outcomes for all students, plus key indicators of institute effectiveness, that is used and updated regularly to improve conditions and practices affecting student and staff success $[10,15]$.

\section{In Conclusion}

OBE is an educational approach considered in planning, implementing and evaluation of curricula rather than an event occurring in the curricula. It promises high level of learning for all students based on the achievement of clearly unambiguous outcomes with consideration to the appropriateness of each learner's development level and assuring active and experienced-based learning. It provides the learner with the destination of the educational journey before voyaging.

\section{Conflict of interest: none}

\section{References:}

[1 $\quad$ Harden, R.M., Davis, M.H. \& Crosby, J.R. (1997). The new Dundee medical curriculum: a whole that is greater than the sum of the parts, Medical Education, 31, 264-271.

[2] McNeil P H., Hughes CS, Toohey SM \&Dowton SB (2006). An innovative outcomes-based medical education, program built on adult learning principles. Medical Teacher, Vol. 28, No. 6,. 527-534

[3] Harden, R.M. (2002a) Developments in outcome-based education, Medical Teacher, 24, 117-120.

[4] Harden, R.M., Crosby, J.R. \& Davis, M.H. (1999). AMEE Guide No. 14: Outcome-based education: Part 1—an introduction to outcome based education, Medical Teacher, 21, 7-14.

[5] Schwartz, M.R. \&Wojtczak, A. (2002) Global minimum essential requirements: a road towards competence-oriented medical education, Medical Teacher, 24, 125-129.

[6] Australian Medical Council (2002) Assessment and Accreditation of Medical Schools: Standards and Procedures, AMC, Canberra).

[7] Simpson, J.G., Furnance, J., Crosby, J., Cummings, A.D., Evans, P.A., Friedman, M., et al. (2002) The Scottish doctor-learning outcomes for the medical undergraduate in Scotland: a foundation for competent and reflective practitioners, Medical Teacher, 24, $136-143$.

[8] Harden, R.M. (1986). Ten questions to ask when planning a course or curriculum. ASME Medical Education booklet no 20, Medical Education, 20, 356-365.

[9] Spady, W. (1988). Organizing for results: the basis of authentic restructuring and reform.Educational Leadership. Vol. 46, No. 2 48 .

[10] Spady, W. (1993).Outcome-based Education.Belconnen, ACT: Australian Curriculum Studies Association.

[11] Accreditation Council on Graduate Medical Education (ACGME) (2001) ACGME outcome project Available : http://www.acgme.org/outcome/comp/compFull.asp

[12] Harden R.M. and Dent J .A. (2005). A Practical Guide for Medical Teachers $.2^{\text {nd }}$ edition, Elsevier Churchill Livingstone ISBN 044310083 ch.14,pp.124-133

[13] Willis, S. and Kissane, B. (1995). Systemic Approaches to Articulating and Monitoring Expected Student Outcomes. Murdoch, Western Australia: Murdoch University.

[14] Mckernan, J. (1993) Perspectives and imperatives: some limitations of outcome-based education, Journal of Cur $r$ iculum and Supervision, 8(4), 343-353.

[15] Towers, J.M. (1996). 'An elementary school principal's experience with implementing an outcome-based curriculum'.Catalyst for Change. Vol. 25, 19-23. 